\title{
Exploring the validity of the Glidewell-
}

\section{Lloyd extension of Clar's $\pi$-sextet rule.}

\section{Assessment from polycyclic conjugated} hydrocarbons ${ }^{\dagger}$

\author{
Ouissam El Bakouria, Jordi Poater ${ }^{b, c}$, Ferran Feixas $^{a}$ and Miquel Solà*,a \\ a Institut de Química Computacional i Catàlisi (IQCC) and Departament de Química, \\ Universitat de Girona, Campus Montilivi, 17071 Girona, Spain. E-mail: \\ miquel.sola@udg.edu \\ ${ }^{b}$ Departament de Química Inorgànica i Orgànica \& Institut de Química Teòrica i \\ Computacional (IQTCUB), Universitat de Barcelona, Martí i Franquès 1-11, 08028 \\ Barcelona, Catalonia, Spain. \\ c Institució Catalana de Recerca i Estudis Avançats (ICREA), Pg. Lluís Companys 23, \\ 08010 Barcelona, Catalonia, Spain
}

\begin{abstract}
The Clar $\pi$-sextet rule was formulated as a tool to qualitatively assign the local aromatic character of six-membered rings in benzenoid species. This simple rule has been widely validated both experimentally and theoretically. In 1984, Glidewell and Lloyd reported an extension of this rule to polycyclic conjugated hydrocarbons having rings with any even number of carbon atoms in their structure. In this work, we assess the validity of the Glidewell-Lloyd extension in 69 polycyclic conjugated hydrocarbons composed of different combinations of four-, six-, and eight-membered rings. Our results support the validity of this extension with some exceptions that are discussed. Finally, a minor modification to the rule is proposed.
\end{abstract}

Keywords: Glidewell-Lloyd's rule $\cdot$ Clar's $\pi$-sextet rule $\cdot$ Polycyclic conjugated hydrocarbons $\cdot$ Aromaticity $\cdot$ Clamped benzenes $\cdot$ double bonds in ring junctions

† This work is dedicated to Prof. Dr. Alberto Vela as a proof of our admiration for his brilliant contributions to chemistry 


\section{Introduction}

The renowned Hückel $4 n+2 \pi$-electron rule [1-4] states that monocyclic conjugated hydrocarbons (annulenes) of $D_{\mathrm{Nh}}$ symmetry with $4 n+2 \pi$-electrons are aromatic. The origin of this rule is the particular molecular orbital distribution in $D_{\mathrm{Nh}}$ annulenes that generates closed-shell electronic structures for a number of $\pi$ electrons equal to $4 n+2$. This closed-shell electronic structure provides aromatic stabilization. Hückel's $4 n+2 \pi$-electron rule is strictly valid only for conjugated monocyclic systems. Several attempts were made to extend this rule to polycyclic aromatic hydrocarbons (PAHs). Among them, probably the most popular was Clar's $\pi$-sextet rule formulated in 1972 [5, 6]. Clar's $\pi$-sextet rule states that the Kekulé resonance structure with the largest number of disjoint aromatic $\pi$-sextets, i.e., benzene-like moieties, is the most important resonance structure for the characterization of PAHs properties. Aromatic $\pi$-sextets were defined by Clar as six $\pi$-electrons localized in a single benzene-like ring separated from adjacent rings by formal $\mathrm{C}-\mathrm{C}$ single bonds. For instance, application of this rule to phenanthrene indicates that its outer rings are expected to have a higher local aromaticity than the central ring, which in fact was confirmed using different measures of local aromaticity [7].

Clar's $\pi$-sextet rule can be applied only to PAHs having six-membered rings (6MRs), i.e., benzenoid species. In 1984, Glidewell and Lloyd [8] proposed to extent the Clar rule to non-benzenoid polycyclic conjugated hydrocarbons (PCHs). Glidewell and Lloyd's rule [8] affirms that the total population of $\pi$-electrons in conjugated polycyclic systems tends to form the smallest $4 n+2$ groups and to avoid the formation of the smallest $4 n$ groups. Scheme 1 shows four non- 
benzenoid PCHs discussed by Glidewell and Lloyd [8] in which application of their rule leads to the conclusion that one of the resonance structures (in red in Scheme 1) is more relevant than the others to explain the electronic and molecular properties of these species. For instance, for bicyclodeca[6.2.0]pentaene (top left chart of Scheme 1), which is composed by fused cyclooctatetraene and cyclobutadiene rings, the resonance structure that better defines the molecular and electronic structure of this compound is the one that places eight $\pi$-electrons in the 8-MR and two in the 4-MR.

Scheme 1, here

Clar's rule is a particular case of the application of the Glidewell and Lloyd rule to benzenoid species. Somewhat unexpectedly given the chemical importance of non-benzenoid PCHs [9-13], Glidewell and Lloyd's rule is not widely known in the chemical community. To our knowledge, there are neither experimental nor theoretical works analyzing the soundness of this rule, except for the systems studied with the semiempirical MNDO method in the original manuscript by Glidewell and Lloyd [8]. We consider that the time is ripe to examine this rule in deeper detail. Thus, the main aim of this work is to study by means of density functional theory (DFT) calculations the validity of this rule. To this end, we will analyze the molecular and electronic structure of 69 PCHs composed of different combinations of four-, six-, and eight-membered rings as shown in Scheme 2. We anticipate here that for most of the studied compounds (but not all) the GlidewellLloyd rule is fully obeyed.

Scheme 2, here 


\section{Methods}

All geometry optimizations were performed with the Gaussian 09 package [14] by using the B3LYP [15-17] hybrid density functional and the 6-311G(d,p) basis set [18] without symmetry constraints. Analytical Hessians were computed to confirm that the optimized structures are indeed minima (zero imaginary frequencies). Except otherwise noted, all reported calculations were carried out in the lowest-lying singlet closed-shell state (ground state for most of the systems studied). In some cases and, in particular, in all cases where the singlet closedshell was not the ground state, open-shell calculations were done using the unrestricted formalism. The aromaticity of each ring was evaluated at the same level of theory by means of two electronic indicators $[19,20]$ such as the multicenter electron sharing index (MCI) $[20,21]$ and the aromatic fluctuation index (FLU) [22], and one geometric descriptor like the harmonic oscillator model of aromaticity (HOMA) [23, 24]. MCI [21] provides a measure of electron sharing among the atoms considered and it is defined as a sum of all the $I_{\text {ring }}$ values resulting from the permutations of indices $A_{1}, A_{2}, \ldots, A_{N}$ (N is the number of atoms in the ring):

$$
\operatorname{MCI}(\mathcal{A})=\frac{1}{2 N} \sum_{P(\mathcal{A})} I_{\text {ring }}(\mathcal{A})
$$

where $P(\mathcal{A})$ stands for a permutation operator which interchanges the atomic labels $A_{1}, A_{2} \ldots A_{N}$ to generate up to the $N$ ! permutations of the elements in the string $\mathcal{A}$. The $I_{\text {ring }}$ index [25] is defined as:

$$
I_{\text {ring }}(\mathcal{A})=\sum_{i_{1}, i_{2}, \ldots i_{N}} n_{i_{1}} \ldots n_{i_{N}} S_{i_{1} i_{2}}\left(A_{1}\right) S_{i_{2} i_{3}}\left(A_{2}\right) \ldots S_{i_{N} i_{1}}\left(A_{N}\right)
$$


$n_{i}$ being the occupancy of molecular orbital (MO) $i$ and $S_{i j}(A)$ the overlap between MOs $i$ and $j$ within the molecular space assigned to atom $A$. For the calculation of FLU [22], delocalization indices (DIs) [26-28], which are a measure of electron sharing between two atoms, are required. At the Hartree-Fock level or with the density functional theory (DFT) approach (in this case we use the non-interacting wavefunction derived from Kohn-Sham orbitals), the DI between atoms $A_{1}$ and $A_{2}$ is obtained from the expression:

$$
\delta\left(A_{1}, A_{2}\right)=2 \sum_{i j} S_{i j}\left(A_{1}\right) S_{i j}\left(A_{2}\right)
$$

where the summations run over all occupied spin MOs of the molecule.

On the other hand, FLU is given by:

$$
F L U(\mathcal{A})=\frac{1}{N} \sum_{i=1}^{N}\left[\left(\frac{V\left(A_{i}\right)}{V\left(A_{i-1}\right)}\right)^{\alpha}\left(\frac{\delta\left(A_{i}, A_{i-1}\right)-\delta_{r e f}\left(A_{i}, A_{i-1}\right)}{\delta_{r e f}\left(A_{i}, A_{i-1}\right)}\right)\right]^{2}
$$

where the string $\mathcal{A}=\left\{A_{1}, A_{2}, \ldots, A_{N}\right\}$ contains the ordered elements according to the connectivity of the $\mathrm{N}$ atoms in a ring and $A_{0} \equiv A_{N}$ and $V\left(A_{i}\right)$ is defined as:

$$
V\left(A_{i}\right)=\sum_{A_{j} \neq A_{i}} \delta\left(A_{i}, A_{j}\right)
$$

$\alpha$ is a simple function to make sure that the first term is always greater or equal to 1, thus taking the values:

$$
\alpha= \begin{cases}1 & V\left(A_{i}\right)>V\left(A_{i-1}\right) \\ -1 & V\left(A_{i}\right) \leq V\left(A_{i-1}\right)\end{cases}
$$

Although several partitions can be used to define the atomic regions needed to calculate DIs and MCIs [29], we made use of the molecular partition based on the quantum theory of atoms in molecules (QTAIM) [30, 31]. MCI and DI indices were obtained with the ESI-3D program $[22,32]$ using the overlaps between occupied molecular orbitals in the atomic basins generated by AIMall program [33]. For MCI 
and HOMA, the larger the values of a given ring, the higher its aromaticity; whereas for FLU, the closer to zero, the more aromatic.

\section{Results and discussion}

The series of PCHs considered in our study are depicted in Scheme 2 (see also Table S1 for extra description). We have included molecules having three and four fused rings containing all possible combinations of 4-MRs, 6-MRs, and 8-MRs with three additional requirements to keep a reasonable number of molecules treated: i) the Lewis structure of the molecule (but not necessarily the molecule) has at least a $\mathrm{C}_{2}$ symmetry axis; ii) molecules with junctions connecting three rings (highly strained situations) are not considered; and iii) combinations of only 6MRs are not included because it is already well-known that they follow Clar's rule [34] with only few exceptions (coronene could be one of them [35, 36]). In addition, we have also considered the combinations of a 4- and 6-MR, a 4- and 8MR, and a 6- and 8-MR.

Scheme 2, here

The molecular structure and Cartesian coordinates of all optimized species can be found in the Supporting Information (Figure S1, Table S2). Scheme 2 depicts the covalent Lewis structure that more closely reproduces the geometry of the optimized species. In these structures, double bonds are depicted for the short bonds and single bonds for the long ones. In case we have a ring in which the largest difference between the shortest and longest bond lengths is equal or less than $0.05 \AA$, we have considered that we have a delocalized situation with intermediate in between single and double bonds and we have represented these 
situations by dashed lines. For molecules with two or more 8-MRs (like 5, 6, 19,...), we optimized all possible orientations of the non-planar 8-MRs. We found that relative energies of the different puckered conformers were in the range $0.3-1.5$ $\mathrm{kcal} / \mathrm{mol}$. Given the small energy differences and similar geometrical features, we do not expect significant changes in the aromaticity of the rings when going from one to the other conformer. Consequently, we decided to analyze the aromaticity of only one of the conformers (those drawn in Fig. S1).

By looking at the Lewis structures of Scheme 2, the conclusion is that most of the studied species follow the Glidewell-Lloyd rule, i. e., $\pi$-electrons in conjugated polycyclic systems tend to form the smallest $4 n+2$ groups and to avoid the formation of the smallest $4 n$ groups. This is the case, for instance, of bicyclodeca[6.2.0]pentaene (Mol. 2). The $10 \pi$-electrons are distributed $2 \pi$ in the 4-MR and $8 \pi$ in the $8-\mathrm{MR}$, avoiding placing $4 \pi$ in the 4-MR. Comparison of $\mathrm{C}-\mathrm{C}$ bond lengths in our optimized structure of 2 and the X-ray structure [37] for a substituted derivative of $\mathbf{2}$ (9,10-diphenylbicyclodeca[6.2.0]pentaene) shows that bond lengths differences are smaller than $0.023 \AA$ (the maximum error occurs in the single bond of the 4-MR adjacent to the ring junction), thus providing confidence in our B3LYP/6-311G(d,p) optimized geometries. However, there are some systems that do not follow the trend expected from the Glidewell-Lloyd rule. In particular, molecules $\mathbf{1 2}, \mathbf{1 8}, \mathbf{2 9}, \mathbf{3 4}, \mathbf{5 1}$, and $59(9 \%$ of the molecules in the set studied) break the rule. For instance, the 4-MR B of molecule $\mathbf{1 2}$ has $4 \pi$-electrons and this is not what one would expect from Glidewell-Lloyd's rule. One could argue that the 4-MR B of molecule 4 has also $4 \pi$-electrons but, in this case, there is no way to avoid having at least one 4-MR with $4 \pi$-electrons, and, therefore, the rule is obeyed. From the set of molecules that follow the Glidewell-Lloyd rule, one can 
also extract interesting conclusions. For this reason, we divide this section into two parts. In the first part, we analyze the set of molecules that obey GlidewellLloyd's rule. In the second one, we discuss the reasons for the breakdown of the Glidewell-Lloyd rule in the six particular cases found.

\section{Polycyclic conjugated hydrocarbons that obey Glidewell-Lloyd's rule}

Table S3 collects the relative energies of all isomers with the same ring types. Moreover, the values of the MCI index of aromaticity for all rings of the analyzed PCHs are given in Table 1 . This Table also contains the MCI values of cyclobutadiene, benzene, and cyclooctatetraene in the closed-shell singlet ground

state and the lowest-lying triplet state for comparison purposes. Benzene is aromatic in the ground state and antiaromatic in the lowest-lying triplet state [38] (Baird's rule [39]). The opposite is true for cyclobutadiene and cyclooctatetraene. The values for the FLU and HOMA descriptors of aromaticity are given in the Supporting Information (Tables S4 and S5). In general, the aromaticity trends given by the different indices coincide.

Table 1, here

The $4 n+2$ Hückel rule strictly holds for monocyclic systems like cyclobutadiene or benzene. The breakdown of this rule in PAHs was already well recognized in the beginning of the fifties [40]. A first attempt to extent the Hückel $4 n+2 \pi$-electron rule from monocyclic annulenes to PAHs corresponded to Platt's ring perimeter model [41]. According to this model, PAHs can be divided into two parts: a perimeter and an inner core. The perimeter is considered as an annulene and the inner core represents only a perturbation of the perimeter. The aromatic character of the PAH is that of the annulene of the perimeter as derived from Hückel's rule. Although this rule can explain the aromaticity of PAHs such as 
pyrene or coronene, it presents many exceptions in PCHs. For instance, bicyclodeca[6.2.0]pentaene (Mol. 2) with $10 \pi$ electrons in its perimeter is antiaromatic (at least the 8-MR), despite following Hückel's rule. Other examples of the failure of the Platt's ring perimeter model are $\mathbf{1 7}, \mathbf{3 2}, \mathbf{3 3}$, or $\mathbf{3 4}$. In other cases, the situation is less clear. For instance, $\mathbf{2 4}$ should be considered antiaromatic according to the Platt's ring perimeter model but it has an antiaromatic 8-MR, an aromatic 6-MR, and two non-aromatic 4-MRs. In general, Platt's ring perimeter model fails to indicate aromaticity in PCHs.

Results on clamped benzenes and cyclooctatetraenes represent another source of interesting information. In general, significant bond length alternation is achieved when the benzene ring is annelated with clamping groups such as cyclopropa-, cyclobuta-, and cyclobutadiene clamps [42-45]. However, as shown by Soncini et al. [42] using ring currents and by some of us [46-48] using different electronic, magnetic, and geometric indices of aromaticity, the aromatic character of the benzene ring changes only slightly. By comparing the clamping effect on a benzene ring of a cyclobutadiene (Mol. 1) and cyclooctatetraene (Mol. 3) clamps, one concludes that the cyclobutadiene clamp localizes stronger than the cyclooctatetraene ring (compare also the structures of $\mathbf{2 3}$ and $\mathbf{2 7}$ given in the Supporting Information (Figure S1)). In the case of two clamped units attached to the benzene ring, the localization effect of two clamps is larger if they are located in meta than in para (compare $\mathbf{7}$ and $\mathbf{8}$ or $\mathbf{2 0}$ and $\mathbf{2 1}$ - for the latter pair see Figure S1). Comparison of isomers 24 and 27 provides support to the idea that 4-MRs when fused to 8-MRs results in more stable molecules than when clamped to 6MRs (see Table S3). For three clamped rings, 4-MRs (32) again have stronger localization effects than 8-MRs (39). In all these cases, the more localized the 6- 
MRs, the lower their aromaticities, with the exception of rings $\mathbf{2 0}$ and $\mathbf{2 1}$ that have similar aromaticities according to all indices. In biphenylene (16), a 4-MR joins two 6-MRs. In this case, the localizing effect of the 4-MR is somewhat weaker than in 1. In fact, molecules having a 4-MR joining two 6- or 8-MRs are more stable than the corresponding isomers with an external 4-MR (compare in Table S3, for instance, 16 and 17, 18 and 19, 30 and 31, 44-47, 48 and 49, and 58-62). Interestingly, Mol. 18 that disobeys the Glidewell-Lloyd rule is more stable than $\mathbf{1 9}$ that follows it, in a similar manner as $\mathbf{1 6}$ is more stable than $\mathbf{1 7}$ (even though these latter two molecules they follow the rule). Another interesting case is given by 31, in which the 6-MR fused to a 4-MR (ring C) is more aromatic and has a more delocalized $\pi$-system than ring D with a clamped 8-MR. This result is somewhat unexpected from the effects of clamping 4- and 8-MRs discussed above. However, there is an explanation. There are two possibilities to locate a $\pi$-sextet in ring D. In one of them, one has to locate $4 \pi$-electrons (two double bonds) in the 4-MR and this situation is unfavorable according to the Glidewell-Lloyd rule. Another option is to have $\pi$-sextets in rings $\mathrm{D}$ and $\mathrm{C}$ and $2 \pi$-electrons in the 4-MR. However, these double bond in the 4-MR has to be located in the ring junction between the 8- and the 4-MR, and as we will see later this situation is avoided as much as possible. Therefore, the most representative Lewis structure of $\mathbf{3 1}$ is the one depicted in Scheme 2.

As already said, cyclobutadiene clamps in benzene rings reduce their aromaticity. Interestingly, when fused to cyclooctatetraene rings, the clamps most often decrease the antiaromaticity of these 8-MRs as indicated by the electronic indices of aromaticity (see MCI results for 10-12, 19, 24, 25, 33, 45, 51, 53-56). Similarly, all indices of aromaticity show that 4-MRs increase their aromaticity as compared 
to cyclobutadiene when fused to generate PCHs. The only exceptions correspond to ring $\mathrm{B}$ of $\mathbf{3 4}$ and rings $\mathrm{A}$ and $\mathrm{B}$ of $\mathbf{5 9}$. These rings are found by $\mathrm{MCI}$ (but not by FLU nor HOMA) somewhat more antiaromatic than cyclobutadiene. 34 and 56 are two molecules that disobey Glidewell-Lloyd's rule and will be discussed in the next subsection.

With some exceptions, the aromaticity of all 4- and 8-MRs in the PCHs studied increase with respect to that of cyclobutadiene and cyclooctatetraene, while that of the 6-MRs decreases as compared to benzene. For 4-MRs, MCI values are in the range $0.007-0.398$ e (reference value of cyclobutadiene is 0.009 e), whereas MCIs of 6-MRs vary between $0.006-0.063$ e (benzene reference value is $0.073 \mathrm{e}$ ) and for 8-MRs MCIs are found in between $0.000-0.0041$ e $(0.001 \mathrm{e}$ is the reference value of cyclooctatetraene). From these values, it becomes evident that the antiaromaticity of 8-MRs is quite constant, irrespective of the formal number of $\pi$ electrons $(2,4,6$, or 8$)$ in the ring, whereas that of 4 - and 6-MRs can change quite a lot depending on the PCH considered. It is worth mentioning that $\mathbf{3 2}$ represents the only example in which, in a given molecule, the 4-MRs are more aromatic than the 6-MR as shown by all indices used in this work.

It is well-known that kinked polycyclic benzenoids are more stable than linear ones [49]. The paradigmatic example is phenanthrene that is more stable than anthracene by about 4-8 $\mathrm{kcal} / \mathrm{mol}$ because of better $\pi$-interactions [49]. Apparently, the situation is reproduced when 6-MRs are replaced by 8-MRs and 6 is more stable than 5 by $3.7 \mathrm{kcal} / \mathrm{mol}$ at the B3LYP/6-311G(d,p) level of theory. It is likely that the reason is not because of better $\pi$-interactions in this case, since all 8-MRs of $\mathbf{5}$ and $\mathbf{6}$ have similar antiaromaticities. Same situation is found when comparing $\mathbf{7}$ and $\mathbf{8}$. Again kinked $\mathbf{8}$ is more stable than linear $\mathbf{7}$, in this case by 17.0 
$\mathrm{kcal} / \mathrm{mol}$. From the aromaticity indices, it seems that $\mathbf{7}$ is more aromatic than $\mathbf{8}$, and, therefore, the reason for the higher stability of $\mathbf{8}$ is not likely to be better $\pi$ interactions. Although this kinked rule of stability seems to be quite general, in fact, it is not and, for instance, $\mathbf{1 3}$ and $\mathbf{1 4}$ are isoenergetic or linear $\mathbf{1 0}$ and $\mathbf{2 0}$ are more stable than kinked 11 and 21 by 2.5 and $2.8 \mathrm{kcal} / \mathrm{mol}$, respectively.

Finally, there are three molecules that follow the Glidewell-Lloyd rule in its lowlying closed-shell singlet state but for which the ground state is an open-shell singlet (O-SS) with the triplet being a low-lying excited state. These are molecules 4, 9, and 57 that have three and two adjacent 4-MRs. In 4, one of the 4-MRs have $4 \pi$-electrons. In 9 and 57, one of the 4-MRs have a double bond in the ring junction between two 4-MRs. In these molecules, the ring junction between two 4-MRs breaks and the molecule forms a biradical 6-MR with a structure analogous to that of $p$-benzyne (henceforth, we name these species with the prefix BR, see Scheme 3). For BR-4, the 0-SS state is 7.0 more stable than the triplet (in $p$-benzyne this difference is about 4-6 kcal/mol [50]) and 57.9 more stable than the closed-shell singlet of 4. This situation was already discussed by Dewar and Li in 1974 comparing butalene (two fused 4-MRS) and $p$-benzyne using the MINDO/3 method [51]. The aromaticity of the 6-MR in the ground state of BR-4 is significantly less than that of the 6-MR in $\mathbf{1}$. The same behavior is observed for 9 . In that case, the O-SS state of BR-9 is more stable by $2.7 \mathrm{kcal} / \mathrm{mol}$ and 61.3 than the triplet of BR-9 and the closed-shell singlet states of 9, respectively. The higher stability of the O-SS with respect to the triplet is attributed to the existence of some 1,4-interaction in the benzyne ring [50]. For BR-57, the O-SS is more stable than the triplet by $9.1 \mathrm{kcal} / \mathrm{mol}$ and more stable than the closed-shell singlet structure by $23.5 \mathrm{kcal} / \mathrm{mol}$. 
Scheme 3, here

Let us finally discuss the case of $\mathbf{5 4}$ and $\mathbf{5 6}$. The most stable structure of molecules 54 and 56 in their closed-shell singlet state is shown in black in Scheme 4. Alternative structures depicted in red in Scheme 4 are also minima. They are less stable than those in black by 1.7 and $4.9 \mathrm{kcal} / \mathrm{mol}$, as expected from GlidewellLloyd rule. However, the closed-shell singlet state is not the ground state for these molecules. The ground state is an O-SS state that is 4.3 and $3.2 \mathrm{kcal} / \mathrm{mol}$ more stable for $\mathbf{5 4}$ and 56, respectively, than the closed-shell singlet state. In the O-SS the biradical character is located in rings B that become aromatic as expected from the Baird rule [39].

Scheme 4, here

\section{Polycyclic conjugated hydrocarbons that disobey Glidewell-Lloyd's rule}

As commented above, in the set of molecules studied, there are six molecules disobeying the Glidewell-Lloyd rule in the closed-shell singlet state that are discussed in the following paragraphs. The expected structures for these molecules according to Glidewell-Lloyd's rule are displayed in Scheme 5.

\section{Scheme 5, here}

Molecules 12, 51, and 59 have a similar behavior. In these cases, we have two adjacent 4-MRs that are fused to 6- or 8-MRs. In these systems, the expected Glidewell-Lloyd structure has a double bond located in the ring junction between two 4-MRs that destabilize this situation. For this reason, they break the GlidewellLloyd prediction. For these systems, the O-SS state with a broken $\mathrm{C}-\mathrm{C}$ ring junction between the 4-MRs (see Scheme 3) is the ground state, so one cannot strictly state that the Glidewell-Lloyd is disobeyed in these molecules because the closed-shell 
singlet state is an excited state. For these molecules in the closed-shell singlet state, the location of two double bonds in a 4-MR is less unfavorable than to place double bonds in between two 4-MRs as depicted in Scheme 5. It is likely that these two closed-shell singlet possibilities are not far in energy since compound $\mathbf{9}$ and $\mathbf{5 7}$ prefer to follow the Glidewell-Lloyd rule. For molecules $\mathbf{1 2}, \mathbf{5 1}$, and $\mathbf{5 9}$, the O-SS ground state (i.e., BR-12, BR-51, and BR-59, see Scheme 3) is more stable than the closed-shell singlet by $19.8,7.4$, and $28.0 \mathrm{kcal} / \mathrm{mol}$, respectively. Besides, the O-SS is more stable than the triplet state for BR-12 and BR-51 (by 1.6 and 0.9 $\mathrm{kcal} / \mathrm{mol}$, respectively) but not for BR-59 in which the triplet state is more stable than the $0-S S$ by $10.1 \mathrm{kcal} / \mathrm{mol}$.

Mol. 34 is similar to the group of three molecules discussed in the paragraph above. In the lowest-lying closed-shell singlet state, one of the 4-MRs (ring B) has formally $4 \pi$-electrons. It is worth noting that this molecule is more stable by 4.6 $\mathrm{kcal} / \mathrm{mol}$ in the O-SS state. The biradical character in this state is concentrated mainly in ring $\mathrm{B}$ that becomes Baird aromatic [52] (MCI in rings $\mathrm{A}$ and $\mathrm{B}$ of the ground state of $\mathbf{3 4}$ are 0.031 and 0.053 e, respectively), thus stabilizing the system. In 34, the triplet state lies $2.2 \mathrm{kcal} / \mathrm{mol}$ higher in energy than the 0 -SS ground state.

Because the ground state is not a closed-shell singlet, we consider that Mol. 12, 34, 51, and $\mathbf{5 9}$ do not represent "real" failures of the Glidewell-Lloyd rule. Mol. 29 is a very particular case. To avoid placing a double bond in the ring junction between the 4- and 8-MR as expected from the Glidewell-Lloyd prediction (Scheme 5), the molecule prefers to put $4 \pi$-electrons in 4-MR A. As a consequence, the ring junction between rings $\mathrm{A}$ and $\mathrm{F}$ is elongated to $1.610 \AA \AA$. In this situation, one can consider that instead of rings $\mathrm{A}$ and $\mathrm{F}$, one has a 10 -MR with $10 \pi$-electrons having 
Hückel aromaticity. This result is reinforced from the calculation of the MCI 0.003 e), FLU (0.017), and HOMA (0.553) that prove a certain aromatic character of the 10-MR. The ground state of this molecule is closed-shell singlet and, therefore, has to be considered a real example of failure of the Glidewell-Lloyd rule.

Finally, $\mathbf{1 8}$ is an interesting case that does not follow Glidewell-Lloyd's rule either. The structure predicted by this rule is shown in Scheme 5. The preferred structure depicted in Scheme 2 avoids having two 4n large rings (8-MRs F) paying the price of having one small $4 \mathrm{n}$ ring (4-MR A).

Taking into account these results, one should reformulate the Glidewell-Lloyd rule by writing: "the total population of $\pi$-electrons in conjugated polycyclic hydrocarbons that have a closed-shell singlet ground state tends to form the smallest $4 n+2$ groups and to avoid the formation of the smallest $4 n$ groups, except in the case that avoiding formation of the smallest $4 n$ groups results in the formation of a greater number of large 4n groups".

\section{Conclusions}

In this work, we have investigated the validity of the Glidewell-Lloyd rule in 69 polycyclic conjugated hydrocarbons composed of different combinations of four-, six-, and eight-membered rings. Our results show that most of polycyclic conjugated hydrocarbons in their ground (or lowest-lying) closed-shell singlet state obey the rule. In many of these species, the Platt ring perimeter model does not provide a good account of their aromaticity. The $\pi$-localization effect of cyclobutadiene and cyclooctatetraene clamps in a benzene ring are larger for the former rings. If two clamped groups are attached to a benzene ring, the 
localization effect is larger if they are located in meta than in para. The cyclobutadiene clamps have a different effect when attached to benzene or cyclooctatetraene rings. In benzene, they reduce the aromaticity of the ring, whereas, in cyclooctatetraene, is the antiaromaticity that is diminished. Although not always, in most cases, kinked polycyclic benzenoids are more stable than linear ones. We found three types of situations in which the Glidewell-Lloyd rule breaks down. First, compounds having adjacent cyclobutadiene rings fused to sixor eight-membered rings. These systems have either 4-MRs with $4 \pi$-electrons or double bonds in the ring junction between 4-MRs. For these systems, the openshell singlet state with a broken $\mathrm{C}-\mathrm{C}$ ring junction between the adjacent cyclobutadiene rings is the ground state. In these molecules, the closed-shell singlet state that disobeys the rule is an excited state and it is well-know that rules of aromaticity change in excited states $[39,53]$. So, strictly speaking the GlidewellLloyd is not disobeyed in these systems. Second, conjugated polycyclic systems try to avoid as much as possible the presence of double bonds in ring junctions. In some cases, this leads to structures that disobey the Glidewell-Lloyd rule, like in 29. And third, there is the situation of $\mathbf{1 8}$ that places $4 \pi$-electrons in one cyclobutadiene ring to avoid placing $8 \pi$-electrons in two cyclooctatetraene rings. This seems a reasonable solution and, therefore, we propose a minor modification of the Glidewell-Lloyd rule to include this case. In this new formulation the rule states: "the total population of $\pi$-electrons in conjugated polycyclic systems that have a closed-shell singlet ground state tends to form the smallest $4 n+2$ groups and to avoid the formation of the smallest $4 n$ groups, except in the case that avoiding formation of the smallest $4 \mathrm{n}$ groups results in the formation of a greater number of large 4 n groups". 
Finally, let us mention that although we have considered only polycyclic conjugated hydrocarbons constituted by an even number of carbon atoms, it is likely that the rule applies to polycyclic conjugated hydrocarbons with an odd number of carbon atoms with $4 n$ or $4 n+2 \pi$-electrons like benzothienocyclobutadiene or the benzocycloheptatrienium or benzocycloheptatrienide ions [8].

\section{Acknowledgements}

This work has been supported by the Ministerio de Economía y Competitividad (MINECO) of Spain (Project CTQ2014-54306-P) and the Generalitat de Catalunya (project 2014SGR931, Xarxa de Referència en Química Teòrica i Computacional, ICREA Academia 2014 prize for M.S., and grant No. 2014FI_B 00429 to O.E.B.). The EU under the FEDER grant UNGI10-4E-801 (European Fund for Regional Development) has also funded this research.

\section{Supplementary Information}

Molecular structure, relative energies among isomers, and Cartesian coordinates of all optimized polycyclic conjugated hydrocarbons studied in this work. FLU and HOMA aromaticity values for all rings analyzed.

\section{References}

1. Hückel E (1931) Quantentheoretische Beiträge zum Benzolproblem I. Die Elektronenkonfiguration des Benzols und verwandter Verbindungen. Z Physik 70:104-186

2. Hückel E (1931) Quanstentheoretische Beiträge zum Benzolproblem II. Quantentheorie der induzierten Polaritäten. Z Physik 72:310-337

3. Hückel E (1932) Quantentheoretische Beiträge zum Problem der aromatischen und ungesättigten Verbindungen. III. Z Physik 76:628-648

4. Hückel E (1937) The theory of unsaturated and aromatic compounds. Z Elektrochemie 43:752-788, 827-849

5. Clar E (1972) The Aromatic Sextet. New York: Wiley.

6. Solà M (2013) Forty years of Clar's aromatic $\pi$-sextet rule. Front Chem 1:22 
7. Portella G, Poater J, Bofill JM, Alemany P, Solà M (2005) Local Aromaticity of [n]Acenes, [n]Phenacenes, and [n]Helicenes $(n=1$ - 9). J Org Chem 70:25092521

8. Glidewell C, Lloyd D (1984) MNDO study of bond orders in some conjugated bi- and tri-cyclic hydrocarbons. Tetrahedron 40:4455-4472

9. Vol'pin ME (1960) Non-Benzenoid Aromatic Compounds and the Concept of Aromaticity. Russ Chem Rev 29:129-160

10. Randić M (2003) Aromaticity of polycyclic conjugated hydrocarbons. Chem Rev 103:3449-3605

11. Ginsburg D (1959) Non-Benzenoid Aromatic Compounds. Ginsburg D, (ed). New York: Interscience Publishers.

12. Breslow R (2014) Novel Aromatic and Antiaromatic Systems. Chem Rec 14:1174-1182

13. Miyoshi H, Nobusue S, Shimizu A, Tobe Y (2015) Non-alternant nonbenzenoid kekulenes: the birth of a new kekulene family. Chem Soc Rev 44:65606577

14. Frisch MJ, Trucks GW, Schlegel HB, Scuseria GE, Robb MA, Cheeseman JR, Scalmani G, Barone V, Mennucci B, Petersson GA, Nakatsuji H, Caricato M, Li X, Hratchian HP, Izmaylov AF, Bloino J, Zheng G, Sonnenberg JL, Hada M, Ehara M, Toyota K, Fukuda R, Hasegawa J, Ishida M, Nakajima T, Honda Y, Kitao O, Nakai H, Vreven T, Montgomery Jr. JA, Peralta JE, Ogliaro F, Bearpark M, Heyd JJ, Brothers E, Kudin KN, Staroverov VN, Kobayashi R, Normand J, Raghavachari K, Rendell A, Burant JC, Iyengar SS, Tomasi J, Cossi M, Rega N, Millam JM, Klene M, Knox JE, Cross JB, Bakken V, Adamo C, Jaramillo J, Gomperts R, Stratmann RE, Yazyev O, Austin AJ, Cammi R, Pomelli C, Ochterski JW, Martin RL, Morokuma K, Zakrzewski VG, Voth GA, Salvador P, Dannenberg JJ, S. Dapprich, Daniels AD, Farkas Ö, Foresman JB, Ortiz JV, Cioslowski J, Fox DJ. Gaussian 09, Revision A.02 ed. Pittsburgh, PA: Gaussian, Inc.; 2009.

15. Becke AD (1993) Density-functional thermochemistry. III. The role of exact exchange. J Chem Phys 98:5648-5652

16. Lee C, Yang W, Parr RG (1988) Development of the Colle-Salvetti correlation-energy formula into a functional of the electron density. Phys Rev B 37:785-789

17. Stephens PJ, Devlin FJ, Chabalowski CF, Frisch MJ (1994) Ab Initio Calculation of Vibrational Absorption and Circular Dichroism Spectra Using Density Functional Force Fields. J Phys Chem 98:11623-11627

18. Frisch MJ, Pople JA, Binkley JS (1984) Self-consistent molecular orbital methods 25. Supplementary functions for Gaussian basis sets. J Chem Phys 80:3265-3269

19. Poater J, Duran M, Solà M, Silvi B (2005) Theoretical Evaluation of Electron Delocalization in Aromatic Molecules by Means of Atoms in Molecules (AIM) and Electron Localization Function (ELF) Topological Approaches. Chem Rev 105:3911-3947

20. Feixas F, Matito E, Poater J, Sola M (2015) Quantifying aromaticity with electron delocalisation measures. Chem Soc Rev 44:6434-6451

21. Bultinck P, Ponec R, Van Damme S (2005) Multicenter bond indices as a new measure of aromaticity in polycyclic aromatic hydrocarbons. J Phys Org Chem 18:706-718 
22. Matito E, Duran M, Solà M (2005) The aromatic fluctuation index (FLU): A new aromaticity index based on electron delocalization. J Chem Phys 122:014109 23. Kruszewski J, Krygowski TM (1972) Definition of aromaticity basing on the harmonic oscillator model. Tetrahedron Lett 13:3839-3842

24. Krygowski TM (1993) Crystallographic studies of Inter- and IntraMolecular Interactions Reflected in benzenoid Hydrocarbons. Nonequivalence of Indices of Aromaticity. J Chem Inf Comp Sci 33:70-78

25. Giambiagi M, de Giambiagi MS, dos Santos CD, de Figueiredo AP (2000) Multicenter bond indices as a measure of aromaticity. Phys Chem Chem Phys 2:3381-3392

26. Bader RFW, Stephens ME (1975) Spatial localization of the electronic pair and number distributions in molecules. J Am Chem Soc 97:7391-7399

27. Fradera X, Austen MA, Bader RFW (1999) The Lewis model and beyond. J Phys Chem A 103:304-314

28. Fradera X, Poater J, Simon S, Duran M, Solà M (2002) Electron-pairing analysis from localization and delocalization indices in the framework of the atoms-in-molecules theory. Theor Chem Acc 108:214-224

29. Matito E, Poater J, Solà M, Duran M, Salvador P (2005) Comparison of the AIM Delocalization Index and the Mayer and Fuzzy Atom Bond Orders. J Phys Chem A 109:9904-9910

30. Bader RFW (1990) Atoms in Molecules: A Quantum Theory. Oxford: Clarendon.

31. Bader RFW (1991) A quantum theory of molecular structure and its applications. Chem Rev 91:893-928

32. Matito E. ESI-3D: Electron Sharing Indexes Program for 3D Molecular Space Partitioning. http://iqc.udg.es/ eduard/ESI. Girona: Institute of Computational Chemistry and Catalysis; 2006.

33. Keith A. AIMall (v. 14.11.23). Overland Park KS, USA: TK Gristmill Software (aim.tkgristmill.com); 2014.

34. Portella G, Poater J, Solà M (2005) Assessment of the Clar's aromatic pisextet rule by means of PDI, NICS, and HOMA indicators of local aromaticity. J Phys Org Chem 18:785-791

35. Zubarev DY, Boldyrev AI (2008) Revealing Intuitively Assessable Chemical Bonding Patterns in Organic Aromatic Molecules via Adaptive Natural Density Partitioning. J Org Chem 73:9251-9258

36. Popov IA, Boldyrev AI (2012) Chemical Bonding in Coronene, Isocoronene, and Circumcoronene. Eur J Org Chem 2012:3485-3491

37. Kabuto C, Oda M (1980) Crystal and molecular structure of 9,10diphenylbicyclo[6.2.0]decapentaene a $10 \pi$ aromatic compound. Tetrahedron Lett 21:103-106

38. Papadakis R, Ottosson $\mathrm{H}$ (2015) The excited state antiaromatic benzene ring: a molecular Mr Hyde? Chem Soc Rev 44:6472-6493

39. Baird NC (1972) Quantum organic photochemistry. II. Resonance and aromaticity in the lowest 3.pi..pi.* state of cyclic hydrocarbons. J Am Chem Soc 94:4941-4948

40. Roberts JD, Streitwieser A, Regan CM (1952) Small-Ring Compounds. X. Molecular Orbital Calculations of Properties of Some Small-Ring Hydrocarbons and Free Radicals1. J Am Chem Soc 74:4579-4582 
41. Platt JR (1949) Classification of Spectra of Cata - Condensed Hydrocarbons. J Chem Phys 17:484-495

42. Soncini A, Havenith RWA, Fowler PW, Jenneskens LW, Steiner E (2002) Control of the diatropic pi ring current in strained benzenes: effects of annelation with cyclopropa, cyclobuta, and cyclobutadieno clampling groups. J Org Chem 67:4753-4758

43. Frank NL, Baldridge KK, Siegel JS (1995) Synthesis and Characterization of Trisbicyclo[2.1.1] hexabenzene, a highly strained bicycloannelated benzene. J Am Chem Soc 117:2102-2103

44. Fowler PW, Havenith RWA, Jenneskens LW, Soncini A, Steiner E (2001) Survival and extinction of delocalised ring currents in clamped benzenes. Chem Commun:2386-2387

45. Grant Hill J, Karadakov PB, Cooper DL (2006) The spin-coupled picture of clamped benzenes. Mol Phys 104:677-680

46. Feixas F, Matito E, Poater J, Solà M (2007) Aromaticity of distorted benzene rings. Exploring the validity of different indicators of aromaticity. J Phys Chem A 111:4513-4521

47. Feixas F, Matito E, Poater J, Solà M (2008) On the Performance of Some Aromaticity Indices: A Critical Assessment Using a Test Set. J Comput Chem 29:1543-1554

48. Solà M, Feixas F, Jiménez-Halla JOC, Matito E, Poater J (2010) A Critical Assessment of the Performance of Magnetic and Electronic Indices of Aromaticity. Symmetry 2:1156-1179

49. Poater J, Visser R, Solà M, Bickelhaupt FM (2007) Polycyclic Benzenoids. Why Kinked is More Stable than Straight. J Org Chem 72:1134-1142

50. Poater J, Bickelhaupt FM, Solà M (2007) Didehydrophenanthrenes: Structure, Singlet-Triplet Splitting, and Aromaticity. J Phys Chem A 111:50635070

51. Dewar MJS, Li W-K (1974) MINDO [modified intermediate neglect of differential overlap]/3 study of the bisdehydrobenzenes. J Am Chem Soc 96:55695571

52. Feixas F, Vandenbussche J, Bultinck P, Matito E, Solà M (2011) Electron delocalization and aromaticity in low-lying excited states of archetypal organic compounds. Phys Chem Chem Phys 13:20690-20703

53. Rosenberg M, Dahlstrand C, Kilså K, Ottosson H (2014) Excited State Aromaticity and Antiaromaticity: Opportunities for Photophysical and Photochemical Rationalizations. Chem Rev 114:5379-5425 
Table 1. The MCI values (units are electrons) for the rings in the closed-shell singlet state of the studied species and for cyclobutadiene, benzene, and cyclooctatetraene in closed-shell singlet and lowest-lying triplet states.

\begin{tabular}{|c|c|c|c|c|c|c|c|c|}
\hline MCI & \multicolumn{2}{|c|}{ 4-MR } & \multicolumn{3}{|c|}{ 6-MR } & \multicolumn{3}{|c|}{ 8-MR } \\
\hline System & Ring A & Ring B & Ring C & Ring D & Ring E & Ring F & Ring G & Ring $H$ \\
\hline Mol. 1 & 0.0214 & & 0.0507 & & & & & \\
\hline Mol. 2 & 0.0257 & & & & & 0.0002 & & \\
\hline Mol. 3 & & & 0.0618 & & & 0.0008 & & \\
\hline Mol. 4 & 0.0244 & 0.0398 & & & & & & \\
\hline Mol. 5 & & & & & & 0.0008 & 0.0007 & \\
\hline Mol. 6 & & & & & & 0.0007 & 0.0001 & 0.0000 \\
\hline Mol. 7 & 0.0160 & & 0.0601 & & & & & \\
\hline Mol. 8 & 0.0283 & & 0.0150 & & & & & \\
\hline Mol. 9 & 0.0171 & 0.0259 & 0.0550 & & & & & \\
\hline Mol. 10 & 0.0299 & & & & & 0.0021 & & \\
\hline Mol. 11 & 0.0294 & & & & & 0.0023 & & \\
\hline Mol. 12 & 0.0338 & 0.0318 & & & & 0.0029 & & \\
\hline Mol. 13 & & & 0.0614 & & & 0.0006 & & \\
\hline Mol. 14 & & & 0.0621 & & & 0.0005 & & \\
\hline Mol. 15 & & & 0.0381 & 0.0333 & & 0.0009 & & \\
\hline Mol. 16 & 0.0213 & & 0.0560 & & & & & \\
\hline Mol. 17 & 0.0265 & & 0.0188 & 0.0505 & & & & \\
\hline Mol. 18 & 0.0367 & & & & & 0.0041 & & \\
\hline Mol. 19 & 0.0280 & & & & & 0.0012 & 0.0001 & \\
\hline Mol. 20 & & & 0.0518 & & & 0.0008 & & \\
\hline Mol. 21 & & & 0.0531 & & & 0.0008 & & \\
\hline Mol. 22 & & & 0.0585 & & & 0.0002 & 0.0008 & \\
\hline Mol. 23 & 0.0231 & & 0.0351 & & & 0.0009 & & \\
\hline Mol. 24 & 0.0285 & & 0.0516 & & & 0.0013 & & \\
\hline Mol. 25 & 0.0313 & & 0.0136 & & & 0.0016 & & \\
\hline Mol. 26 & 0.0293 & 0.0283 & 0.0091 & & & 0.0007 & & \\
\hline Mol. 27 & 0.0308 & & 0.0074 & & & 0.0029 & & \\
\hline Mol. 28 & 0.0264 & & 0.0590 & & & 0.0006 & & \\
\hline Mol. 29 & 0.0093 & & 0.0369 & & & -0.0011 & & \\
\hline Mol. 30 & 0.0230 & & 0.0393 & 0.0616 & & 0.0006 & & \\
\hline Mol. 31 & 0.0185 & & 0.0393 & 0.0155 & & -0.0004 & & \\
\hline Mol. 32 & 0.0275 & & 0.0059 & & & & & \\
\hline Mol. 33 & 0.0285 & 0.0277 & & & & 0.0017 & & \\
\hline Mol. 34 & 0.0290 & 0.0089 & & & & -0.0006 & & \\
\hline Mol. 35 & & & 0.0623 & 0.0628 & & 0.0003 & & \\
\hline Mol. 36 & & & 0.0610 & 0.0337 & 0.0375 & 0.0006 & & \\
\hline Mol. 37 & & & 0.0610 & 0.0101 & & 0.0004 & & \\
\hline
\end{tabular}




\begin{tabular}{|c|c|c|c|c|c|c|c|c|}
\hline Mol. 38 & & & 0.0150 & 0.0477 & & 0.0008 & & \\
\hline Mol. 39 & & & 0.0462 & & & 0.0008 & & \\
\hline Mol. 40 & & & 0.0629 & & & 0.0008 & 0.0001 & 0.0008 \\
\hline Mol. 41 & & & 0.0587 & & & 0.0001 & 0.0007 & 0.0002 \\
\hline Mol. 42 & & & 0.0605 & & & 0.0004 & 0.0001 & \\
\hline Mol. 43 & & & 0.0497 & & & 0.0008 & 0.0001 & 0.0007 \\
\hline Mol. 44 & 0.0273 & & & & & 0.0003 & 0.0011 & \\
\hline Mol. 45 & 0.0282 & & & & & 0.0013 & 0.0002 & 0.0008 \\
\hline Mol. 46 & 0.0266 & & & & & 0.0013 & 0.0002 & 0.0007 \\
\hline Mol. 47 & 0.0272 & & & & & 0.0008 & 0.0007 & \\
\hline Mol. 48 & 0.0284 & & 0.0371 & 0.0277 & 0.0125 & & & \\
\hline Mol. 49 & 0.0214 & & 0.0456 & 0.0238 & 0.0558 & & & \\
\hline Mol. 50 & 0.0146 & & 0.0210 & 0.0377 & & & & \\
\hline Mol. 51 & 0.0385 & & & & & 0.0031 & & \\
\hline Mol. 52 & 0.0277 & & & & & 0.0003 & 0.0007 & \\
\hline Mol. 53 & 0.0307 & & & & & 0.0020 & 0.0029 & \\
\hline Mol. 54 & 0.0278 & 0.0140 & & & & 0.0010 & -0.0007 & \\
\hline Mol. 55 & 0.0278 & & & & & 0.0013 & & \\
\hline Mol. 56 & 0.0300 & 0.0147 & & & & 0.0014 & 0.0003 & \\
\hline Mol. 57 & 0.0248 & & 0.0517 & & & & & \\
\hline Mol. 58 & 0.0204 & 0.0230 & 0.0502 & 0.0518 & & & & \\
\hline Mol. 59 & 0.0080 & 0.0074 & 0.0240 & 0.0299 & & & & \\
\hline Mol. 60 & 0.0237 & & 0.0304 & & & & & \\
\hline Mol. 61 & 0.0155 & & 0.3144 & & & & & \\
\hline Mol. 62 & 0.0163 & & 0.0303 & & & & & \\
\hline Mol. 63 & & & 0.0323 & & & 0.0009 & & \\
\hline Mol. 64 & & & 0.0613 & & & 0.0004 & 0.0002 & \\
\hline Mol. 65 & & & 0.0551 & & & -0.0002 & -0.0002 & \\
\hline Mol. 66 & & & 0.0449 & & & -0.0059 & & \\
\hline Mol. 67 & & & 0.0107 & 0.0583 & & 0.0002 & 0.0020 & \\
\hline Mol. 68 & & & 0.0616 & 0.0136 & & -0.0001 & 0.0006 & \\
\hline Mol. 69 & & & 0.0411 & 0.0276 & & 0.0008 & & \\
\hline Cyclobutadiene & 0.0094 & & & & & & & \\
\hline Benzene & & & 0.0726 & & & & & \\
\hline Cyclooctatetraene & & & & & & 0.0009 & & \\
\hline Cyclobutadiene triplet ${ }^{a}$ & 0.1257 & & & & & & & \\
\hline Benzene tripleta & & & -0.0001 & & & & & \\
\hline Cyclooctatetraene tripleta & & & & & & 0.0275 & & \\
\hline
\end{tabular}

a Species in the lowest-lying triplet state. 
Scheme 1. Different resonance structures for four selected polycyclic conjugated hydrocarbons. Red resonance structures are those that describe better the structural and electronic properties of these polycyclic conjugated hydrocarbons according to the Glidewell-Lloyd rule.
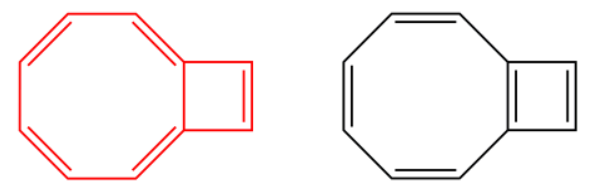<smiles>c1ccc2c(c1)-c1ccccc1-2</smiles><smiles>c1ccc2c(c1)-c1ccccc1-2</smiles><smiles>c1cc2cc3ccc3cc12</smiles><smiles>c1cc2cc3ccc3cc12</smiles>
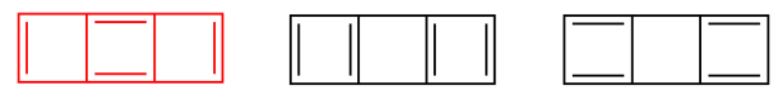
Scheme 2. The 69 polycyclic conjugated hydrocarbons in their closed-shell singlet states with the resonant structure that better defines them from the optimized molecular structure.

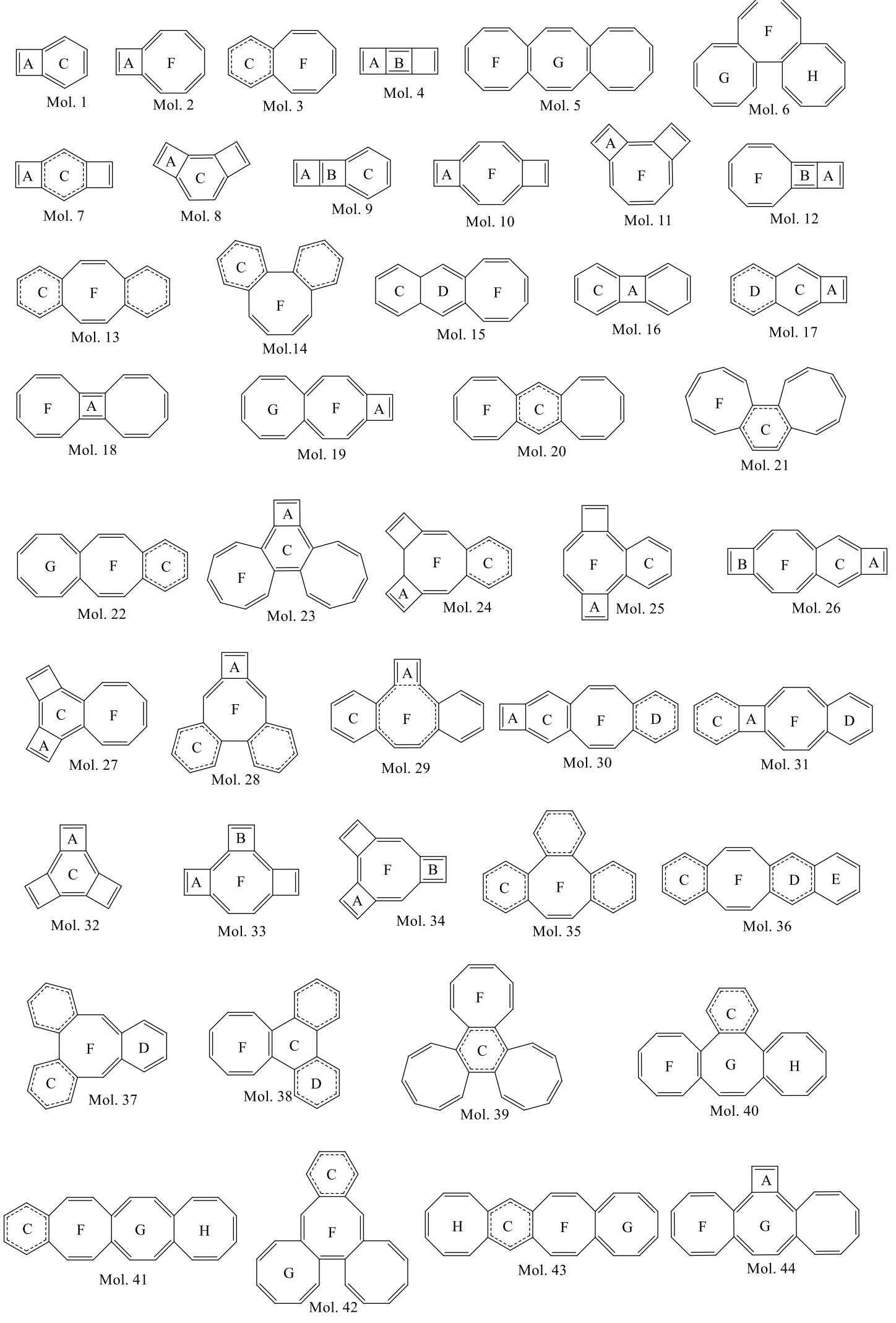



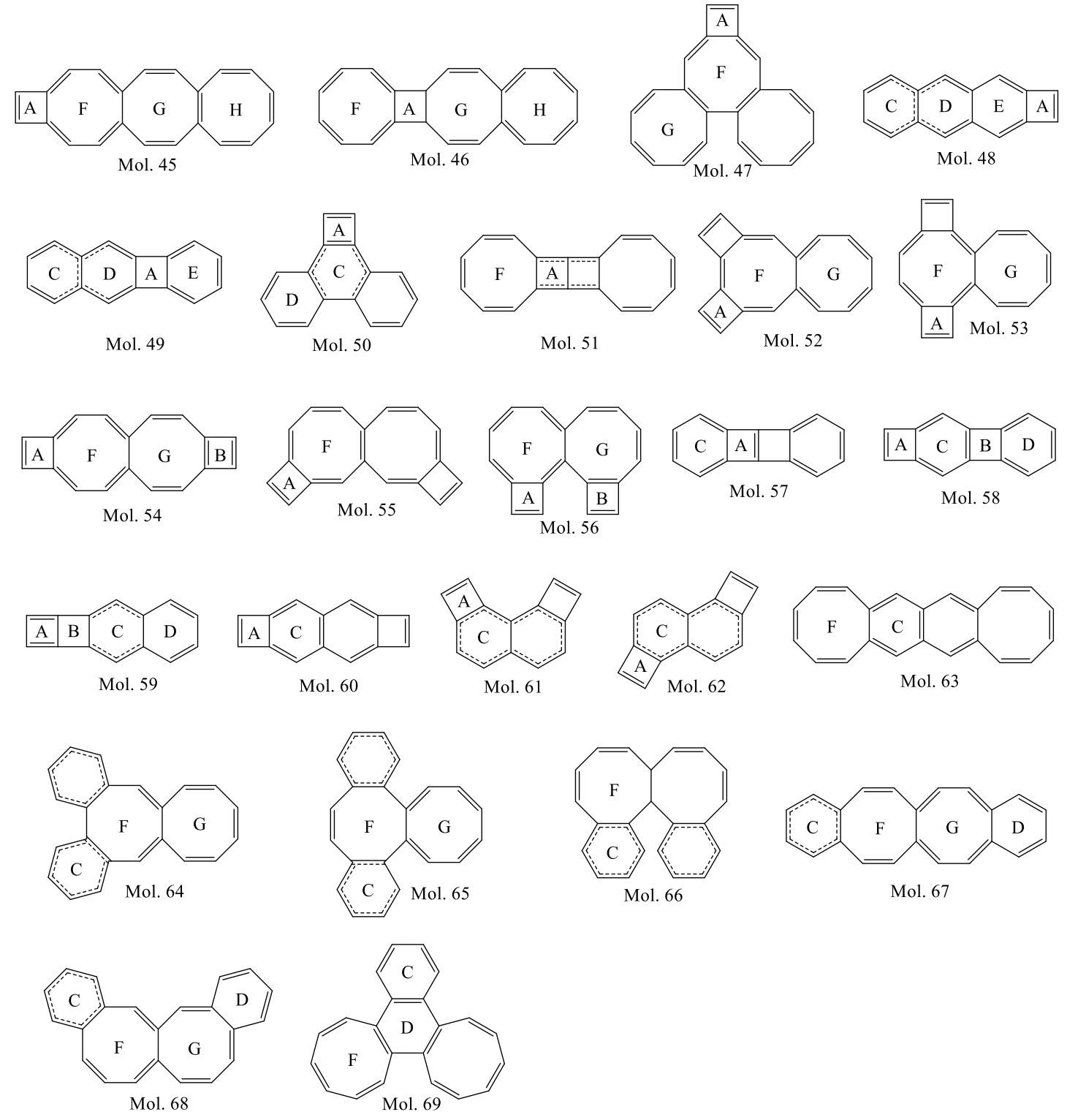
Scheme 3. The polycyclic conjugated hydrocarbons having an open-shell singlet (O-SS) biradical (BR) ground state with the resonant structure that better defines them from the optimized molecular structure.

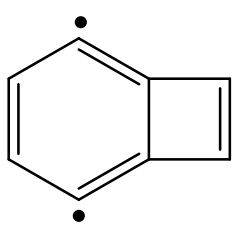

Mol. BR-4 (O-SS biradical)

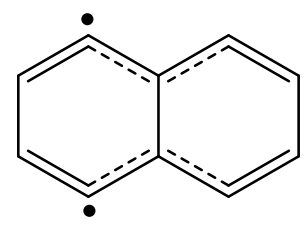

Mol. BR-9 (O-SS biradical)<smiles>C1=C/C=C\C2=CC(=C1)C=CC=C2</smiles>

Mol. BR-12 (O-SS biradical)<smiles>c1cccc2cc3ccccccc3cc2cc1</smiles>

Mol. BR-51 (O-SS biradical)<smiles></smiles>

Mol. BR-57

(O-SS biradical)<smiles>c1ccc2cc3ccccc3cc2c1</smiles>

Mol. BR-59

(O-SS biradical) 
Scheme 4. In black, the most stable structure of molecules 54 and 56 in their closed-shell singlet state. In red, alternative structures of these molecules in their closed-shell singlet state.
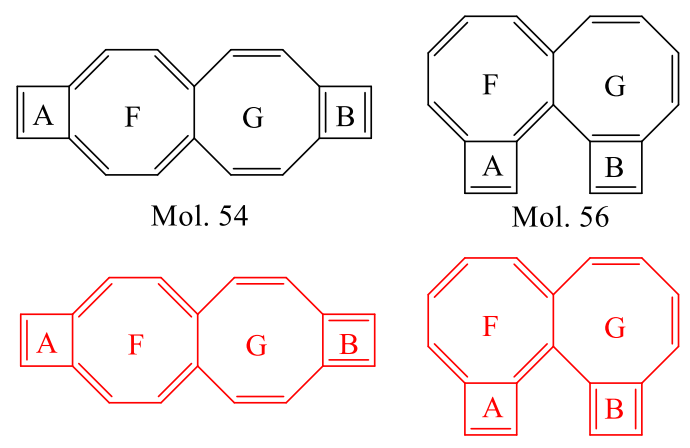
Scheme 5. The predicted structure by Glidewell-Lloyd's rule of the studied polycyclic conjugated hydrocarbons that disobey this rule.

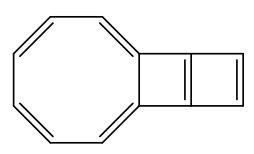

Mol. 12

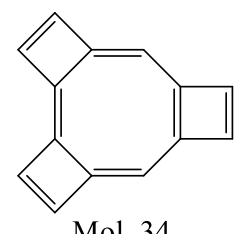

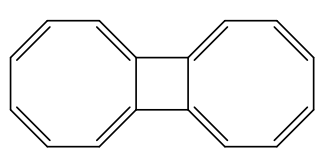

Mol. 18

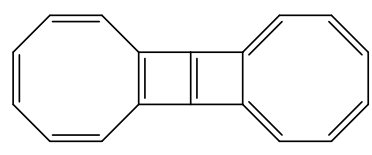

Mol. 51<smiles>c1ccc2c3ccc=3c3ccccc3ccc2c1</smiles>

Mol. 29

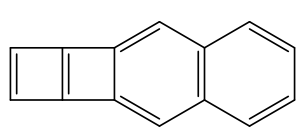

Mol. 59 
TABLE OF CONTENTS GRAPHIC

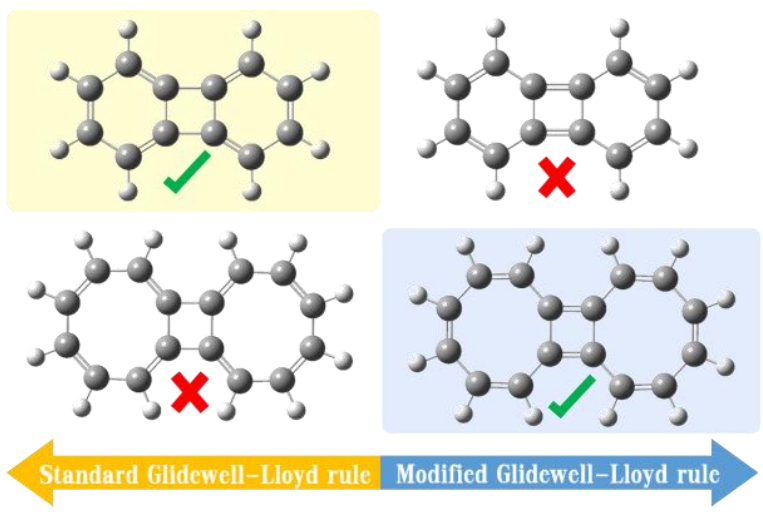

The validity of the Glidewell-Lloyd extension of Clar's $\pi$-sextet rule is explored in 66 polycyclic conjugated hydrocarbons composed of different combinations of four-, six-, and eight-membered rings. 